SINET: Ethiop. J. Sci., 22(2):175-190, 1999

(1) Faculty of Science, Addis Ababa University, 1999

ISSN: 0379-2897

\title{
SPECTRAL DEPENDENT ELECTRICAL CHARACTERISTICS OF THIN FILM A-SI:H SOLAR CELLS
}

\author{
Ulrich Stutenbäumer and Belayneh Mesfin \\ Department of Physics, Faculty of Science, Addis Ababa University \\ PO Box 1176, Addis Ababa, Ethiopia
}

\begin{abstract}
The illuminated current-voltage characteristics of thin film a-Si:H $\mathrm{p}-\mathrm{i}-\mathrm{n}$ solar cells were measured for the visible and near infrared spectral regions. The fill factor, the conversion efficiency, the open circuit voltage and the short circuit current were compared to the parameters of crystalline silicon pn-junction solar cells. The effect of irradiance and spectral illumination on the cell performance was investigated. Finally, the applicability of the investigated thin film a-Si:H solar cells for its practical operation in Ethiopia is discussed.
\end{abstract}

Key words/phrases: Applicability, a-Si:H solar cells, electrical properties

\section{INTRODUCTION}

The breakthrough towards low-cost photovoltaics (PV) is widely expected from thin-film technology because of the prospect of low material usage and large area processing. A variety of possible thin-film materials exist, ono of which is a-Si:H. It has been applled in amorphoususilicon bused thin flim colar cells (Markvart, 1994).

The structure of an $\mathrm{si}$ solar cell is the pun structure (Fig. 1), Both pand $\mathrm{n}$ layers have poor tuansport propertles. Through the Incorporatlon of an intrinsle (i) a-Si:H layer, the transport properties are improved. Its trapping concentration inside the energy gap is much smaller and additionally the intrinsic electric field of the depletion region extends over the whole intrinsic layer. Therefore, only drift processes are important and diffusion can be neglected. The optimum intrinsic layer is between 400 and $800 \mathrm{~nm}$ thick (Eickhoff et al., 1995) and defines the performance of the solar cell. The i-layer is not completely intrinsic, 
but is slightly $n$-type. It is therefore preferable to have light enter the cell through a very thin (optically inactive) p-type layer, so that the region of maximum photo-generation in the $\mathrm{i}$-layer is also the region of the highest electric field. Additionally there is a transparent conducting oxide (TCO) contact to the p-layer and an ohmic contact to the n-layer.

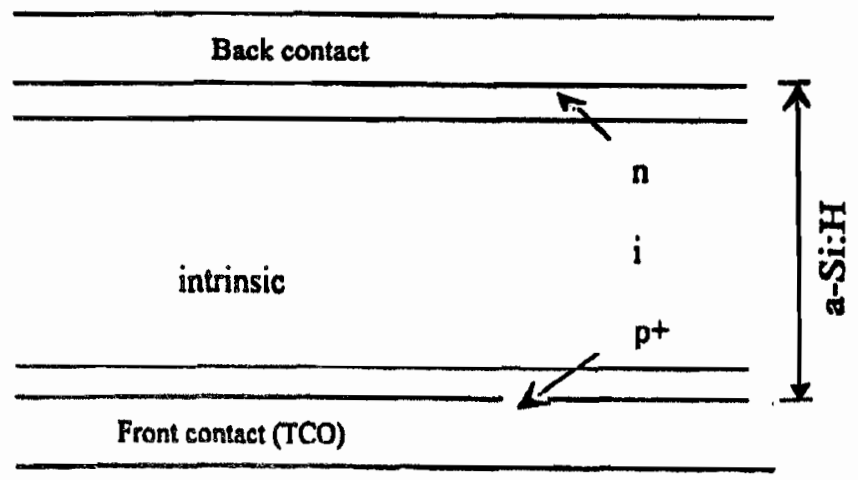

Glass substrate

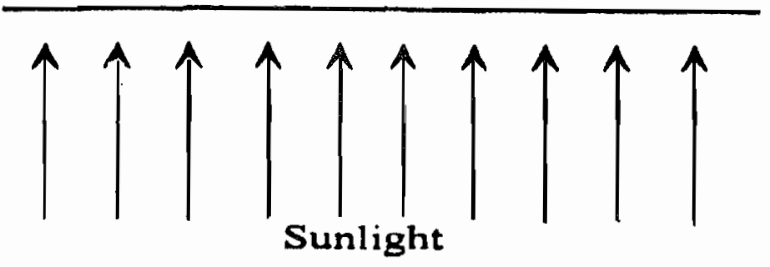

Fig. 1. Schematic diagram of a thin film a-Si:H p-i-n solar cell (Markvart, 1994). TCO abbreviates transparent conducting oxide.

The absorption of light inside the $i$-layer creates additional defects and increases the density of trapping and scattering states and reduces the efficiency of the solar cell. This so called Staebler-Wronski effect (Staebler and Wronski, 1980) depends on the total number of photons absorbed. It therefore depends on the intensity of the light to which the cell is exposed, the duration of the exposure and on the thickness of the i-layer. To become commercially viable as power generators a-Si cells have to deliver over $10 \%$ efficiency after photo degradation (Markvart, 1994). 
After the production of the amorphous thin film solar cell its characterisation can be made by measuring the current-voltage (Iv) relation under defined white light and spectral illumination. The most important characteristic value of a solar cell is its efficiency with the related parameters open circuit voltage $\left(V_{o c}\right)$, short circuit current density $\left(J_{s c}\right)$ and fill factor. In this investigation the spectral irradiance dependence of the cell performance of a-Si: $\mathrm{H}$ thin film p-i-n solar cells with different intrinsic layer thickness are compared with those of commercially available crystalline silicon pn junction solar cells. The usability of the investigated solar cells is discussed in relation to the climatic conditions in Addis Ababa.

\section{MATERIALS AND METHODS}

The current-voltage characteristics were done with the two probes technique using two digital multimeters (DMM) for the voltage and current measurements and a variable load. The optical part consists of one lens $(f=+150 \mathrm{~mm}$ ), aperture, sample holder, different colour filters and a $250 \mathrm{~W}$ stabilised quartz tungsten halogen lamp from Oriel. The temperature on the samples was measured and the temperature drift of voltage and current was taken into account. The light intensity was measured with a calibrated Lux meter using a silicon photo diode.

This investigation of the electrical properties of a-Si:H solar cells was conducted with different solar cell systems. The TCOPIN1 and TCOPIN2 samples consist of a glass substrate coated with a thin conducting oxide $\left(\mathrm{SnO}_{2}\right)$ on top of which a thin p-doped a-Si:H layer is deposited and on top of this an additional intrinsic a-Si:H layer is deposited which has different thickness for the different samples. An additional n-doped a-Si:H layer follows, on top of which is a silver coating as a back contact, which formed a complete solar cell system. The TCOPIN 1 and TCOPIN2 samples were produced by the glow-discharge method at the Research Centre in Jülich (Germany). The samples have effective areas of about $15 \mathrm{~cm}^{2}$ and $9 \mathrm{~cm}^{2}$, respectively. The investigated crystalline silicon p-n-junction (PN) solar cell is a commercially available type produced by Solarex. Its effective area is $25 \mathrm{~cm}^{2}$. 


\section{RESULTS AND DISCUSSION}

Figure 2 shows the I-V curves of the TCOPIN1, TCOPIN2 and PN solar cell samples. The samples were illuminated with light of intensity $100 \mathrm{~mW}(\mathrm{~cm})^{-2}$. The values of the different parameters for each sample are shown in Table 1. The intensity dependent values of the different cell parameters are also tabulated in Table 1 and displayed as graphics in Fig. 5.

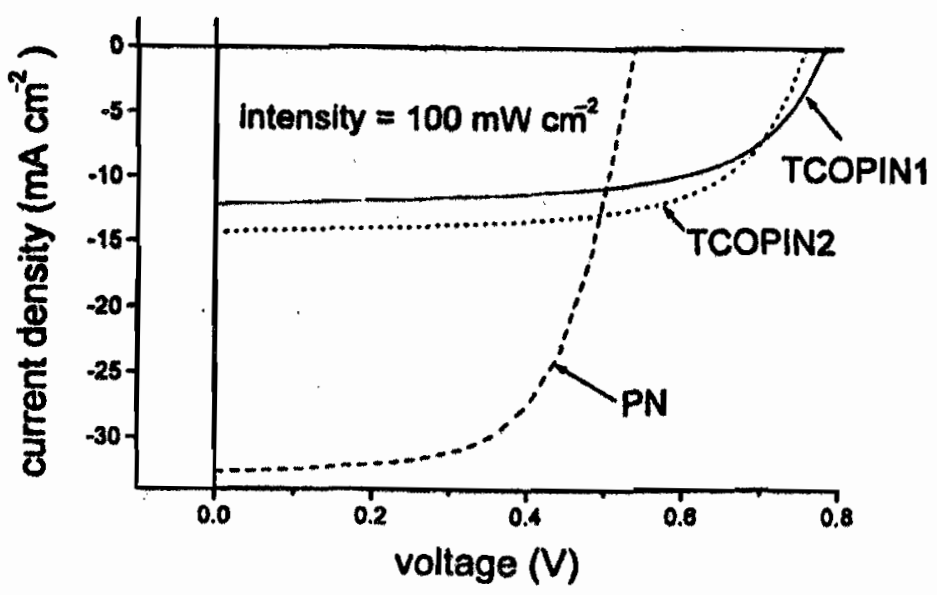

Fig. 2. The I-V curves of the a-Si:H solar cell samples TCOPIN 1 and TCOPIN 2 and the crystalline silicon solar cell PN sample.

Table 1. Cell performance as a function of the intensity of illumination for the TCOPIN1, TCOPIN2 and the PN sample.

\begin{tabular}{llllllllllll}
\hline & \multicolumn{3}{c}{ TCOPIN1 } & \multicolumn{3}{c}{ TCOPIN2 } & \multicolumn{3}{c}{ PN } \\
\hline $\begin{array}{l}\text { Intensity } \\
\left(\mathrm{mW} \mathrm{cm}^{-2}\right)\end{array}$ & 10 & 50 & 100 & 10 & 50 & 100 & 10 & 50 & 100 \\
$\mathrm{~J}_{\mathrm{se}}\left(\mathrm{mA} \mathrm{cm}{ }^{-2}\right)$ & 1.06 & 5.67 & 12.11 & 1.6 & 7.4 & 14.35 & 3.67 & 14.81 & 32.66 \\
$\mathbf{V}_{\text {oc }}$ (volts) & 0.68 & 0.75 & 0.78 & 0.67 & 0.73 & 0.76 & 0.51 & 0.53 & 0.54 \\
Fill Factor & 0.67 & 0.64 & 0.65 & 0.63 & 0.64 & 0.64 & 0.6 & 0.66 & 0.63 \\
Efficiency (\%) & 4.82 & 5.42 & 5.95 & 6.79 & 6.88 & 6.91 & 10.15 & 10.38 & 11.02 \\
\hline
\end{tabular}


It can be observed that the values of the open circuit voltage $\left(V_{\infty}\right)$ for the a$\mathrm{Si}: H$ samples are close to each other, whereas the $\mathrm{V}_{\infty}$ for the crystalline silicon solar cell sample (PN) is small compared to the other samples. The $\mathrm{V}_{\infty}$ is mainly dependent on the band gap of the material under consideration, that is: $V_{\mathbf{O C}}$ $(\max )=\mathrm{E}_{\mathrm{g}} / \mathrm{e}$, where $\mathrm{E}_{\mathrm{g}}$ is the energy gap and $\mathrm{e}$ is the electronic charge. The available open circuit voltage is reduced by recombination losses. A wider band gap material $\left(E_{\mathrm{g}}\right.$ of intrinsic a-Si:H $\sim 1.7 \mathrm{eV}$ ) usually gives rise to a larger $\mathrm{V}_{\mathrm{oc}}$ compared with that of a narrower band gap material $\left(\mathrm{E}_{8}\right.$ of crystalline $\mathrm{Si}$ $\sim 1.1 \mathrm{eV})$.

The relatively large value of the short circuit current density $J_{2 c}$ for the PN solar cell sample arises from the high quality of the crystalline material. Recombination of minority carriers is small and the transport of the carriers is more efficient in the PN sample than that of the a-Si:H samples. Even if the $\mathrm{V}_{\mathrm{oc}}$ for the PN sample is small, the large value of the $J_{w}$ gives rise to a larger efficiency compared with the other samples. The energy conversion capacity of the crystalline silicon solar cell is far superior than that of the investigated a$\mathrm{Si}: H$ solar cells. The intensity dependent I-V characteristics of the TCOPIN 1 and the TCOPIN2 samples are shown in Fig. 3 and of the PN sample in Fig. 4.

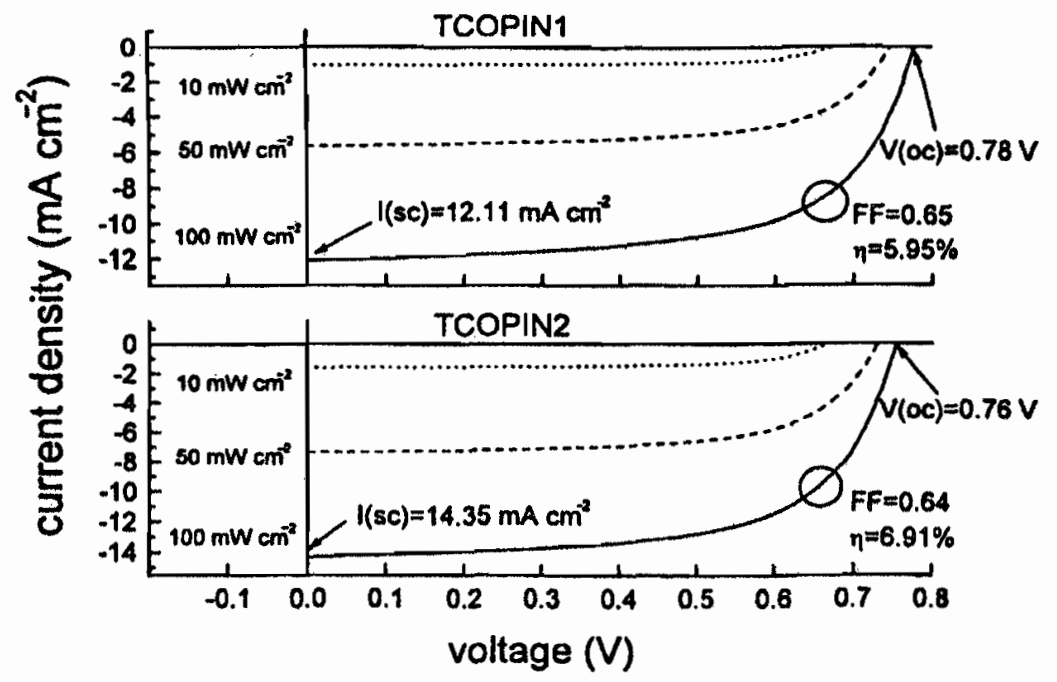

Fig. 3. The intensity dependent I-V curves of the a-Si:H solar cell sample TCOPIN1 (top) and TCOPIN2 (bottom). 


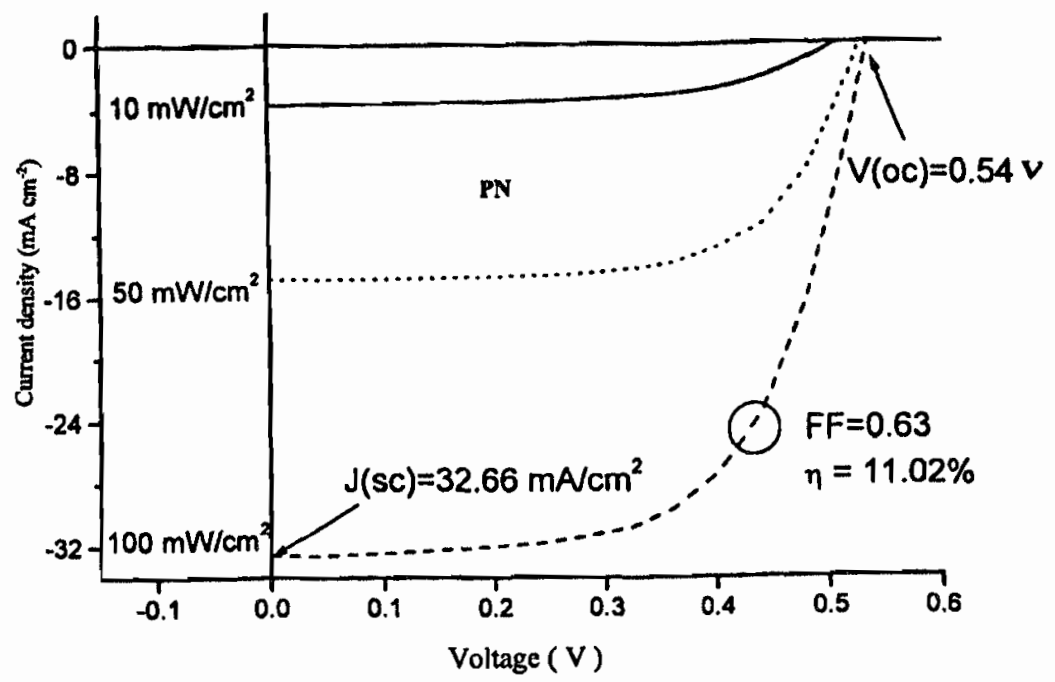

Fig. 4. The intensity dependent I-V curves of the crystalline silicon solar cell PN sample.

It is found that the $\mathrm{J}_{\mathrm{sc}}$ is proportional to the intensity of the incident light. When the intensity of the incident light is increased, the photocurrent increases, because of the increasing photon flux above band gap energy which is capable of producing large numbers of electron-hole pairs. In turn, the generated carriers (the electrons and the holes) are pushed by the built-in electrostatic field to the opposite contacts where they produce a large current collected in the external circuit.

The decrease in the $\mathrm{V}_{\mathrm{c}}$ as the intensity of the incident light is decreased is small compared to the decrease in the $J_{s c}$. For a given solar cell sample, the $V_{o c}$ is mainly dependent on the type of the material (a-Si:H or crystalline $\mathrm{Si}$ in this investigation) rather than on the intensity of the light incident on the sample. It depends logarithmically on the current and also on the irradiance (Markvart, 1994). The variations in the fill factor with increasing intensity are small for all samples.

The efficiency of the rcopin2 sample is found to be greater than that of the TCOPIN1 sample. The basic difference in the two samples is in the i-layer 
thickness, [i.e., the i-layer thickness of the TCOPIN1 sample is about $0.488 \mu \mathrm{m}$ and that of the TCOPIN2 is about $0.983 \mu \mathrm{m}$ (Eickhoff and Stiebig, 1996)]. Hence, it may suggest that as the i-layer thickness increases, the probability for the formation of electron-hole pairs increases which results in an increase in the photocurrent. It is mainly due to an increase of the $J_{\omega c}$ that the variation in the efficiency is observed.

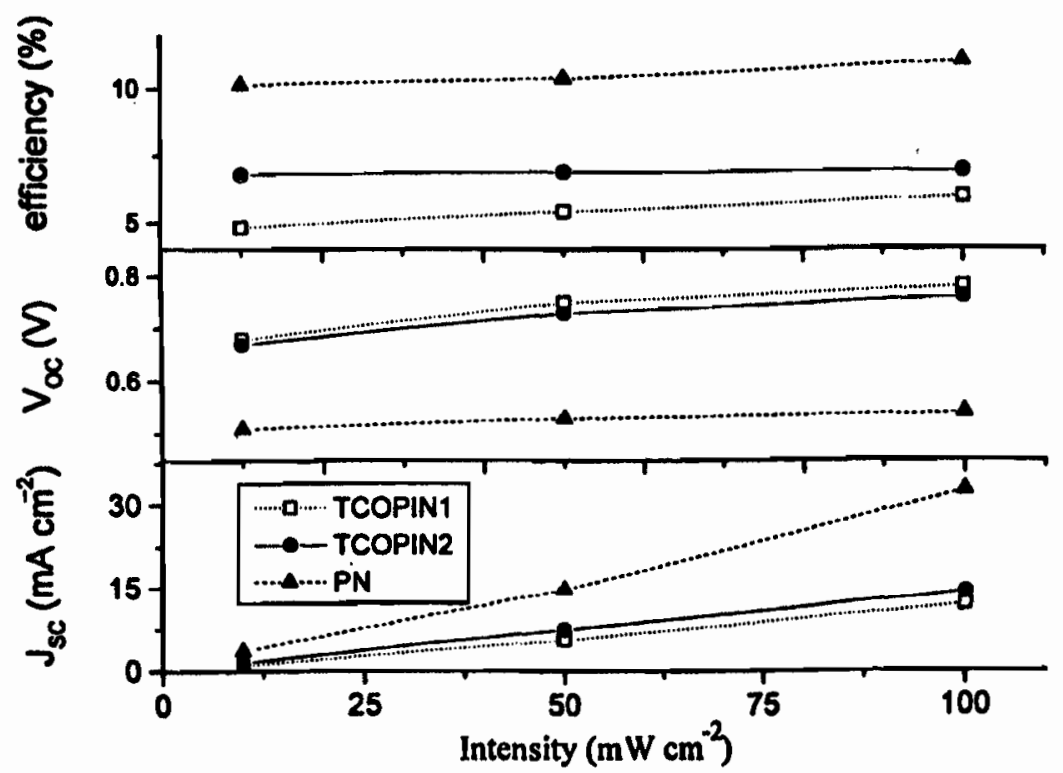

Fig. 5. Cell performance as a function of illuminating intensity for the TCOPIN1, TCOPIN2 and the PN sample.

However, increasing the i-layer thickness has a disadvantage. It needs more material to have thick layers, which increases the cost of manufacturing. The recombination rate will also increase thereby reducing the output current. The Staebler-Wronski effect will also be pronounced when the i-layer thickness is increased (Kruehler, 1993).

The efficiency of the PN sample is approximately two times greater than for the a-Si:H solar cells due to the superior material properties of the crystalline silicon. 
The TCOPIN2 sample shows a slightly smaller open circuit voltage $\mathbf{V}_{o c}$ than the TCOPIN1 sample, since the thicker intrinsic layer has more recombination centres. Generally, the efficiencies of our samples are small compared to $>10$ \% which is achieved by other a-Si:H solar cell producers (Catalano, 1995). Furthermore, the fill factors of the tested solar cells are not very large (compared to 0.74; Green et al., 1995), due to series and shunt resistance losses in these samples. Generally, the fill factor of the TCOPIN1 sample is larger than that of the TCOPIN2 sample. This may be due to the difference in the i-layer thickness. As the layer thickness increases the fill factor decreases due to the decrease in the electric field in the depletion region (Arya, 1988).

One of the reasons for the small efficiencies is that the investigated samples use a flat TCO at the front side to make optical characterisation simple. If the samples were assembled from rough TCO, the efficiencies would have been increased significantly. Also the surfaces of the samples are not textured. Surface texturing and anti reflection coating may have increased the efficiencies by more than $5 \%$ (Bloss et al., 1995).

Two colour filters (blue and red) are used to investigate the effects of the spectral response on the I-V characteristics of the TCOPIN1, the TCOPIN2 and the PN samples. The transmittance of the colour filters was measured with a PerkinElmer Lambda 19 spectrometer and the measured spectra are those shown in Fig. 6. Additionally, the absorption spectra (measured with the Perkin-Elmer Lambda 19 spectrometer) of the TCOPIN1 sample is displayed in this figure and the energy gap position of the intrinsic a-Si:H layer is indicated.

The blue filter transmits between $3.76 \mathrm{eV}$ and $2.07 \mathrm{eV}$ (about 330 and $600 \mathrm{~nm}$ of wavelengths) and the maximum transmittance is obtained at about $2.58 \mathrm{eV}$ $(480 \mathrm{~nm})$ whereas the red filter transmits photon energies below $2.06 \mathrm{eV}$ (wavelengths above $600 \mathrm{~nm}$ ) including the near infrared.

The TCOPIN1, the TCOPIN2 and the PN sample were illuminated with light that is transmitted through the colour filters so that the integrally transmitted photon flux through each filter has an intensity of $50 \mathrm{~mW} \mathrm{~cm}^{-2}$. The resulting I-V characteristics curves obtained for the TCOPIN1 and the TCOPIN2 samples are 
shown in Fig. 7, the spectral dependent I-V curve of the PN sample is shown in Fig. 8.

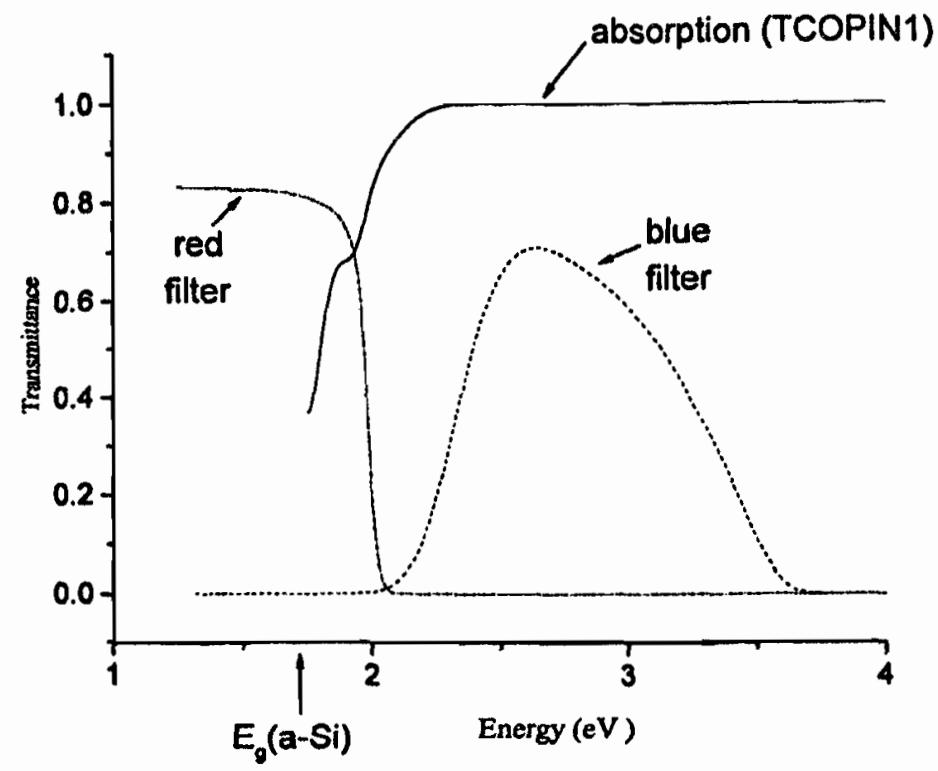

Fig. 6. Transmittance spectra of the spectral filters (blue and red) and the absorption spectrum of the TCOPIN1 sample. The position of the energy gap $\left(\mathrm{E}_{\varepsilon}\right)$ of the intrinsic a-Si:H layer is indicated.

The different electrical parameters of the TCOPIN1, TCOPIN2 and PN samples, obtained when the samples are illuminated to light of different colours, are displayed in Table 2 and the cell performance parameters are graphically presented in Fig. 9.

The open circuit voltages $\left(\mathrm{V}_{\mathrm{oc}}\right)$ of the TCOPIN1 sample under illumination with light of different colours, having equal intensities, does not vary appreciably from each other. This is due to the fact that the $V_{o c}$ mainly depends on the optically active material of the solar cell and the series and shunt resistance associated with the given solar cell (Mazer, 1997). 


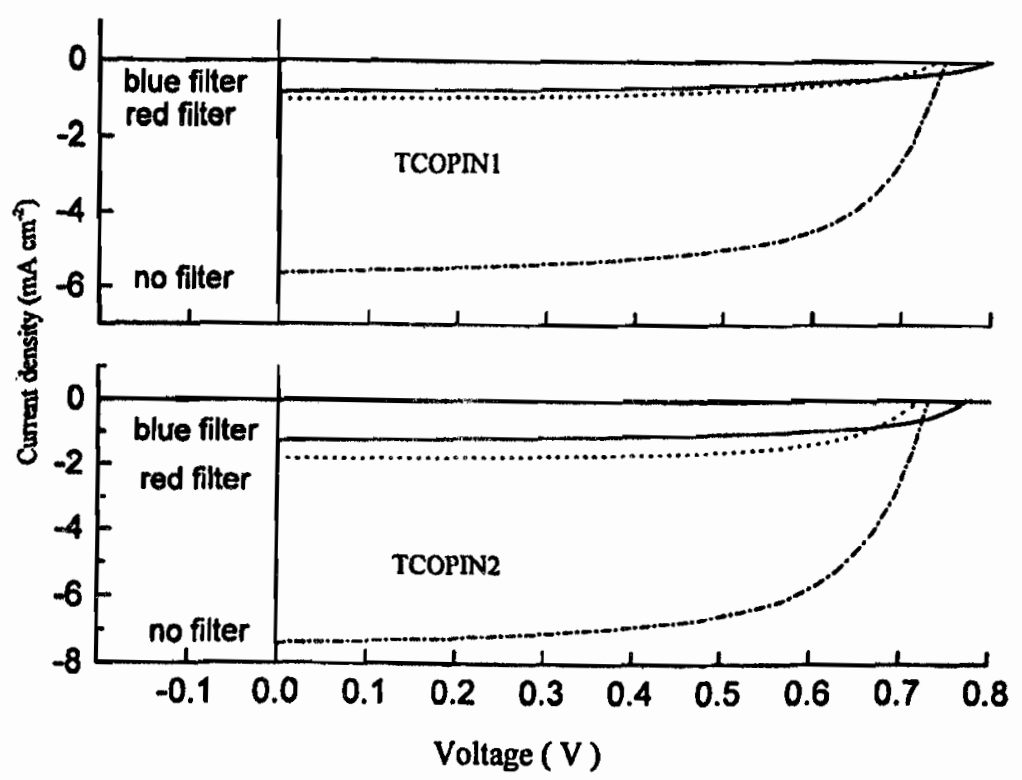

Fig. 7. The spectral dependent I-V curves of the TCOPIN1 sample (top) and the TCOPIN2 sample (bottom) for an intensity of $50 \mathrm{~mW}(\mathrm{~cm})^{-2}$.

It can be observed from Fig. 7 that the variations in the $J_{a c}$ of the TCOPIN1 sample for the different colours of light illumination having the same intensities are large. The $J_{s c}$ of the a-Si:H solar cell samples depend not only on the intensity of the incident photon flux (Fig. 3), but also on the wavelength of the incident light. For the same intensity, those colours of light whose energy is slightly greater than the band gap energy of $\mathrm{a}-\mathrm{Si}: \mathrm{H}\left(\mathrm{E}_{\mathrm{g}}=1.7 \mathrm{eV}\right)$ are able to generate large currents. The red response of the a-Si: $\mathrm{H}$ solar cells (Ellis and Delahoy, 1986) is most pronounced for the TCOPIN2 sample and is a result of the spectral dependent absorption inside the active intrinsic a-Si:H layer. Blue light has a small penetration depth into the intrinsic layer which is much smaller than the layer thickness (Jagannathan et al., 1997). Therefore the blue filtered irradiance on the a-Si:H solar cells generates a smaller $J_{s c}$ and therefore, cell efficiency smaller than with the red filter is observed. Measurements without filters result in a large value of the $\mathrm{J}_{\mathrm{SC}}$ because the spectral region between the red and the blue filter contributes to the irradiation of the sample. 


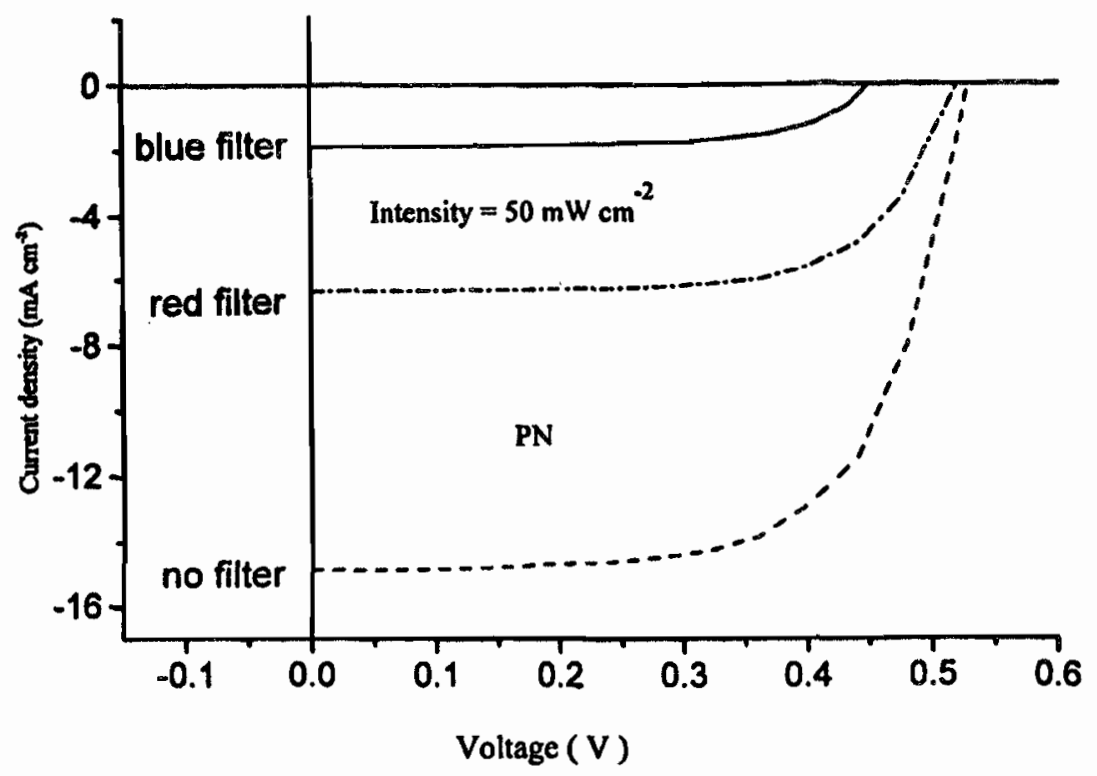

Fig. 8. The spectral dependent I-V curves of the crystalline Si solar cell PN sample.

Table 2. Cell performance as a function of the selected spectral filter for the TCOPIN1, TCOPIN2 and the PN sample.

\begin{tabular}{|c|c|c|c|c|c|c|c|c|}
\hline \multirow[b]{2}{*}{ Filter } & \multicolumn{3}{|c|}{ TCOPIN 1} & \multicolumn{3}{|c|}{ TCOPIN2 } & \multicolumn{2}{|r|}{ PN } \\
\hline & none & blue & red & none & blue & red & none & blue red \\
\hline $\mathrm{J}_{\mathrm{sc}} \mathrm{mA} \mathrm{cm}$ & 12.11 & 0.85 & 1.05 & 14.35 & 1.25 & 1.82 & 32.66 & 1.96 .36 \\
\hline$V_{o c}$ (volts) & 0.78 & 0.8 & 0.74 & 0.76 & 0.78 & 0.72 & 0.54 & 0.450 .52 \\
\hline Fill Factor & 0.65 & 0.51 & 0.53 & 0.64 & 0.57 & 0.63 & 0.63 & 0.650 .67 \\
\hline Efficiency (\%) & 5.95 & 0.69 & 0.82 & 6.91 & 1.12 & 1.64 & 11.02 & 1.124 .43 \\
\hline
\end{tabular}

For the spectral dependent illumination with a photon flux having the same intensity, the efficiency is found to be the largest for red filter illumination. The least value is obtained for the blue filter (Fig. 9). These variations in the efficiency values result mainly not because of the variations in the $V_{o c}$ but due to the variations in the $J_{s c}$. 


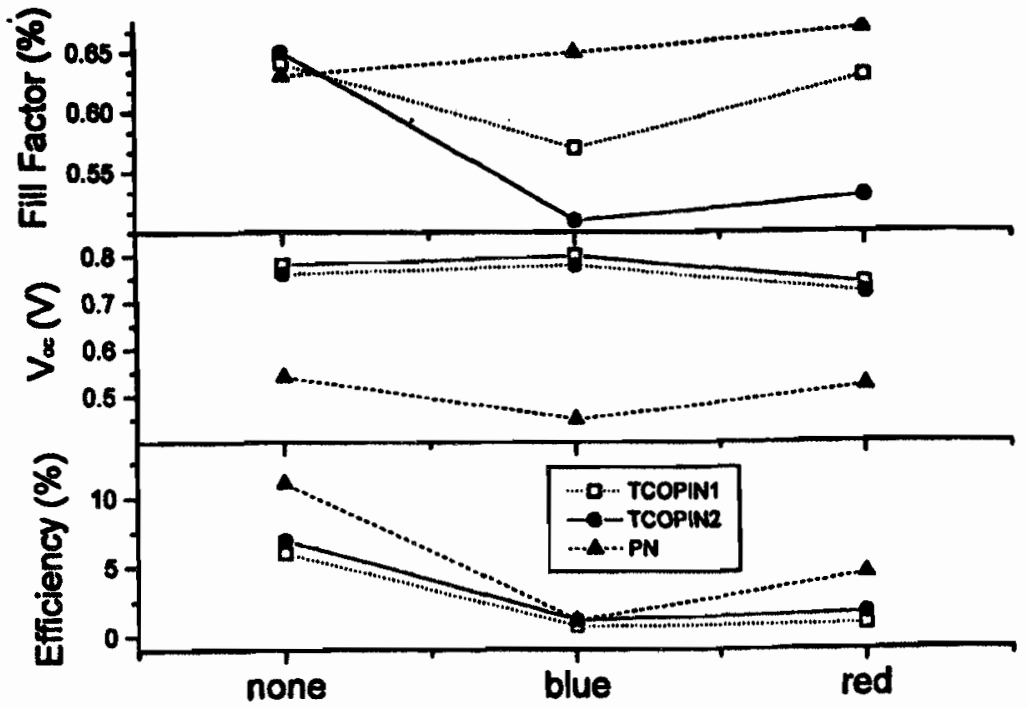

Filter

Fig. 9. Cell performance as a function of the spectral illumination for the TCOPIN1, TCOPIN2 and the PN sample.

Similar to the TCOPIN1 sample, the deviations of the $\mathrm{V}_{\mathrm{oc}}$ values for the TCOPIN2 sample for different filtered-light illumination are small. This seems to confirm that the $V_{\infty}$ does not depend significantly on the energy of light which is incident on the sample. On the other. hand, there is a strong dependence of the fill factor on the spectral dependent illumination for the TCOPIN2 sample. Its red response fill factor is $10 \%$ larger than for the blue response. Penetration of energetic blue photons increases the recombination of electron-hole pairs before they can be separated and hence increase the series resistance of the solar cell. This implies a smaller $J_{a c}$ and consequently a smaller fill factor of the TCOPIN2 sample for the blue response (Mazer, 1997).

The $J_{x}$ for the TCOPIN2 sample is also found to depend on the energy of the incident light. The $J_{\mathrm{Bc}}$ decreases with an increase of energy of the incident light flux. Compared with that of the TCOPIN1 sample, the $J_{\mathfrak{c}}$ values of the TCOPIN2 sample that correspond to a given colour of light illumination are far greater than that of the TCOPIN1 sample. It is the difference in the i-layer thickness (the 
i-layer of the TCOPIN2 sample is almost twice as thick as that of the TCOPIN1 sample) that gives rise to an increase in the value of the $J_{x}$. This improvement of the red response of a-Si:H solar cells by increasing the thickness of the active i-layer is well known (Eickhoff et al., 1995). The corresponding efficiencies of the TCOPIN2 sample is also greater than that of the TCOPIN1 sample. This difference in the efficiency is mainly due to the difference in the value of the $J_{w c}$ for the different colours of light illumination. Like the TCopIN 1 sample, the highest value of spectral dependent efficiency of the TCOPIN2 sample is obtained for red filter illumination and the least efficiency value is obtained for blue filter illumination. With no applied spectral filter the efficiency of the samples is maximised because the spectral region between the red and blue filter is the most efficient for the conversion of photons to generate electron-hole pairs.

The cell performance as a function of the selected spectral filter for the crystalline silicon PN sample differs from the investigated a-Si:H solar cells in some important aspects. The decrease in efficiency, fill factor and $V_{o c}$ for the blue response of the crystalline silicon PN sample is the most pronounced one when compared with the a-Si:H solar cell samples (Table 2 and Fig. 9). Blue light has a very small penetration depth for the relatively thick p-type crystalline silicon layer where the electron-hole pair generation takes place. The generation rate is thus small compared to the red response, where the photon energy is closer to the energy gap of silicon $\left(E_{g}=1.1 \mathrm{eV}\right)$. Therefore, the blue filtered irradiance on the crystalline silicon PN solar cell generates a very small $\mathrm{J}_{S \mathrm{SC}}$ and correspondingly a very small cell efficiency is determined compared to the other colour filter. The efficiency increases to four times its value of the blue response for the red response compared to 1.5 and 1.2 for the TCOPIN2 and TCOPIN1 sample.

The $\mathrm{V}_{\mathrm{o}}$ of the PN sample for the blue response decreases against the value for the red response which is opposite compared to the thin film a-Si:H solar cells where the $V_{o c}$ increases for the blue response. The effective built-in voltage $\left(V_{b i}\right)$ for electron-hole pairs generated in only a thin surface volume due to the small penetration depth of the blue light is apparently smaller than for red light. That indicates that $\left(\mathrm{eV}_{\mathrm{bi}} / \mathrm{E}_{\mathrm{g}}\right)_{\text {blue }}<\left(\mathrm{eV}_{\mathrm{bi}} / \mathrm{E}_{\mathrm{g}}\right)_{\text {rod }}<1$ in the case of crystalline silicon PN solar cells. This results also in a remarkable decrease of the efficiency of crystalline Si PN solar cells for blue light illumination. 
Table 3 summarises the weather dependent intensity distribution for the two colour regions in Addis Ababa (Ethiopia) on culmination of the sun measured on the $2^{\text {at }}$ and $13^{\text {th }}$ of March 1998. If the weather conditions become cloudy; the intensity ratio for the blue and red filter spectral regions increases.

Table 3. Spectral dependent intensity at Addis Ababa (Ethiopia) on culmination of the sun on 2nd and 13th March 1998 for cloudy and sunny weather conditions.

\begin{tabular}{|c|c|c|c|c|}
\hline \multirow{2}{*}{$\begin{array}{l}\text { Weather condition at } \\
\text { Addis Ababa on } 2^{\text {wa }} \text { and } \\
13^{\text {th }} \text { of March } 1998\end{array}$} & & \multicolumn{3}{|c|}{ Filter } \\
\hline & & None & Blue & Red \\
\hline $\begin{array}{l}\text { Sunny } \\
\text { Cloudy }\end{array}$ & Intensity (mW $\left.\mathrm{cm}^{-2}\right)$ & $\begin{array}{c}71 \\
8\end{array}$ & $\begin{array}{l}63 \\
7\end{array}$ & $\begin{array}{c}47 \\
4\end{array}$ \\
\hline
\end{tabular}

For reasons discussed above, the crystalline $\mathrm{Si}$ solar cells show an over pronounced decrease of efficiency if the weather conditions become cloudy compared to the amorphous silicon solar cells.

Our investigation indicates that a PV system installed with crystalline Si PN modules will produce a smaller output power at cloudy weather condition than a PV system of thin film a-Si:H solar cell modules with the same power rating. On the other hand a crystalline Si PN solar cell module will produce more output power in sunny weather conditions with high irradiance intensities than a thin film a-Si:H solar cell module. Our findings would suggest the following interpretation. The approximately four months of the Ethiopian rainy season demands a hybrid PV system of crystalline Si and thin film a-Si:H solar cell modules to obtain optimal efficiency over the whole year. At present the sale prices for thin film a-Si:H solar cell modules (7.3 \$/Wp; CONRAD, 1997) are higher than for crystalline silicon solar cell modules $(5.6 \$ / \mathrm{Wp})$. But this is expected to change in the next few years due to technological advances in module fabrication (Jennings, 1995).

It is recommended that a detailed field test of a PV system consisting of crystalline $\mathrm{Si}$ and thin film a-Si:H solar cells should be conducted in Addis Ababa over a period of a year. 


\section{CONCLUSIONS}

The cell performance as a function of the spectral irradiance for thin film a-Si:H thin film solar cells has an optimum value for the red spectral region at the energy of photons comparable to the energy gap $(\mathrm{Eg}=1.7 \mathrm{eV})$ of the active intrinsic a-Si:H layer. An intrinsic layer thickness of $0.8 \mu \mathrm{m}$ would be optimal to achieve a high cell efficiency. Compared with crystalline silicon solar cells, the efficiency of thin film a-Si:H solar cells are better in cloudy weather conditions. A well chosen solar energy generator system for the climatic conditions of Addis Ababa should consist of a combination of crystalline silicon and thin film a-Si:H solar cell modules.

\section{ACKNOWLEDGEMENTS}

The authors would like to thank the technology group of C. Beneking of Jülich Research Centre (Germany) for preparing some of the samples. We are also very grateful to $T$. Eickhoff of Technical College Bingen (Germany) who supported us with technical assistance and discussions. The International Program in the Physical Sciences (IPPS) of Uppsala University, Sweden is thanked for the purchase of the Perkin Elmer Lambda 19 spectrometer, and the Centre of International Migration (CMM/GTZ) in Germany for financial support.

\section{REFERENCES}

1. Arya, R.R. (1988). High efficiency amorphous silicon based solar cells. In: First International Symposium on Physics and Application of Amorphous Semiconductors, pp. 263-277 (Demichelis, F. ed.) World Scientific, Singapore.

2. Bloss, W.H., Pfisterer, F., Schubert, M. and Walter, T. (1995). Thin-film solar cells, Progress in Photovoltaics: Research and Applications, Vol 3, pp. 3-24.

3. Catalano, A. (1995). a-Si:H-based solar cells. In: Solar Cells and their Applications, pp. 163-184 (Partian, L.D., ed.), Wiley \& Sons, New York.

4. CONRAD (1997). Virtual Electronic Ware House CD-ROM, V. 3.0, Hirschau.

5. Eickhoff, T., Stiebig, H., Reetz, W., Rech, B. and Wagner, H. (1995). Temperature dependence of a-Si:H solar cell parameters - Experiments and numerical simulations. The 13th E.C. Photovoltaic Solar Energy Conference. Nice. 
6. Eickhoff, T. and Stiebig, H. (1996). Modellierung der spektralen Empfindlichkeit von a-Si:H Solarzellen. In: Photovoltaik 3, Forschungsverbund Sonnenenergie, Themen 95/96, pp. 90-98, Köln.

7. Ellis, F.B. and Delahoy, A.E. (1986). Optical properties of hydrogenated amorphous silicon based solar cells. In: Solar Energy Materials 13, pp. 109-132, Amsterdam.

8. Green, M.A., Emery, K., Bücher, K. and King, D.L. (1995). Solar cell efficiency tables (Version 5), Progress in Photovoltaics: Research and Applications, Vol 3, pp. 51-55.

9. Jagannathan, B., Anderson, W.A. and Coleman, J. (1997). Amorphous silicon/ptype crystalline silicon heterojunction solar cells. In: Solar Energy Materials and Solar Cells, Vol. 46, pp. 289-310.

10. Jennings, C. (1995). Terrestrial Off-Grid Photovoltaic Systems. In: Solar Cells and their Applications, pp. 325-335 (Partian, L.D., ed.) Wiley \& Sons, New York.

11. Kruehler, W. (1993). Duennschicht-Solarzellen aus amorphen Halbleitern. In: Solarzellen, pp. 109-118 (Meissner, D., ed.) Vieweg, Braunschweig.

12. Markvart, T. (1994). Thin-film solar cells. In: Solar Electricity, pp. 57-71, Wiley \& Sons, Chichester.

13. Mazer, J.A. (1997). Solar Cells: An Introduction to Crystalline Photovoltaic Technology, pp. 102-110, Kluwer Academic Publishers, Boston.

14. Partian, L.D. (1995). Status, Potential, Conclusion. In: Solar Cells and their Applications, pp. 515-529 (Partian, L.D., ed.) Wiley \& Sons, New York.

15. Staebler, D.L. and Wronski, C.R. (1980). Optically induced conductivity changes in discharge-produced hydrogenated amorphous silicon. J. Appl. Phys. 51:3262. 